\title{
Systemic or intra-amygdala infusion of the benzodiazepine, midazolam, impairs learning, but facilitates re-learning to inhibit fear responses in extinction
}

\author{
Genevra Hart, ${ }^{1}$ Justin A. Harris, ${ }^{2}$ and R. Frederick Westbrook ${ }^{1,3}$ \\ ${ }^{1}$ School of Psychology, The University of New South Wales, Sydney, New South Wales 2052, Australia; ${ }^{2}$ School of Psychology, \\ The University of Sydney, Sydney, New South Wales 2006, Australia
}

\begin{abstract}
A series of experiments used rats to study the effect of a systemic or intra-amygdala infusion of the benzodiazepine, midazolam, on learning and re-learning to inhibit context conditioned fear (freezing) responses. Rats were subjected to two context-conditioning episodes followed by extinction under drug or vehicle, or to two cycles of context conditioning and extinction with the second extinction under drug or vehicle. A 20-min extinction under vehicle resulted in better longterm inhibition on a subsequent drug-free retention test than a 4-min extinction under vehicle, or a 20-min, as well as a 4-min, extinction under drug. However, a 20-min, as well as a 4-min, second extinction under drug was just as effective in producing long-term inhibition as a 20 -min second extinction under vehicle and this inhibition was greater than that produced by a 4-min second extinction under vehicle. Initial extinction of 5, 10, or 20 min were equally effective in producing long-term inhibition when the second extinction under drug was 20 min; and 5-, 10-, or 20-min second extinction under drug were equally effective in producing long-term inhibition when the initial extinction was 5 min. A 4- or 20-min second extinction under an infusion of drug into the basolateral amygdala (BLA) was as effective in producing long-term inhibition as a 20-min second extinction under vehicle and was more effective than a 4-min second extinction under vehicle. The results show that midazolam impairs learning to inhibit fear responses but spares and even facilitates re-learning this inhibition.
\end{abstract}

Extinction of Pavlovian conditioned fear responses in laboratory subjects (e.g., rats) occurs when the signaling relation between initially innocuous cues (e.g., a discrete stimulus such as a noise or the array of cues comprising a context) and a feared outcome (typically, brief but aversive footshock) is broken by exposures to the now conditioned stimulus (CS) in the absence of the feared outcome (the aversive shock unconditioned stimulus [US]). The fear responses (e.g., freezing, potentiated startle) produced by the signaling relation decline across the CS-alone exposures and eventually cease to occur. Fear of the CS is said to have been extinguished. A historically influential explanation of extinction was that breaking the signaling relation destroyed the learning produced by that relation. For example, theories that identified learning with a single construct, such as associative strength (e.g., Rescorla and Wagner 1972) or connection weights (Rumelhart et al. 1986), found it convenient for various purposes to explain extinction as the erasure of this strength or restoration of the original connection weights between the CS and US.

However, it is now clear that this explanation is incomplete at best. Various post-extinction manipulations have been used to show that pairings of the extinguished CS with the US are not necessary for the restoration of fear responses. For example, fear responses recover "spontaneously" with the passage of time since extinction (Quirk 2002; Leung and Westbrook 2008); they are "reinstated" when the extinguished CS is tested either in the presence of (Bouton and Bolles 1979; Westbrook et al. 2002) or

\footnotetext{
${ }^{3}$ Corresponding author.
}

E-mail f.westbrook@unsw.edu.au; fax 61-92-03853044.

Article is online at http://www.learnmem.org/cgi/doi/10.1101//m.1682410. shortly after (Morris et al. 2005) exposure to danger; and fear responses are "renewed" when the CS is tested either outside the context where extinction occurred (Bouton and King 1983; Bouton and Ricker 1994; Harris et al. 2000) or in the absence of drug-related cues present at extinction (Bouton et al. 1990). These restoration phenomena show that much, if not all, of the original learning survives extinction in spite of the fact that the CS fails to elicit fear responding. This implies that extinction involves new learning that co-exists with the old, while inhibiting its expression in fear responding. Moreover, this new learning appears to be tightly controlled by the various cues (physical, temporal, and internal, including emotional state) present across extinction, leading to suppression of fear responses when they are present and restoration of fear when they are absent (for review, see Bouton 1993; Bouton et al. 2006).

Just as extinction does not wipe out the fear learning produced by conditioning, reconditioning does not wipe out the inhibitory learning produced by extinction, in spite of the fact that the CS now elicits fear responding. Rescorla (2001) pointed out that if pairings of an extinguished CS with the US erased inhibitory learning, then a reconditioned CS would fail to show the characteristic products of that learning. However, this does not occur. For example, a CS that has been conditioned, extinguished, and reconditioned continues to show spontaneous recovery of both appetitive- (Rescorla 2001) and fear-conditioned (Leung and Westbrook 2008) responses. Thus, such a CS enters re-extinction with the inhibitory learning produced by the initial extinction intact, but unable to depress the fear responses produced by pairings of the extinguished CS with the US. Although unable to depress these fear responses, the original inhibitory 
learning is activated and strengthened across re-extinction. For example, Quirk (2002) reported that extinguished fear responses were completely restored by a long retention interval. Nevertheless, these spontaneously recovered fear responses exhibited savings: They re-extinguished faster than they initially extinguished. Moreover, distinct neural substrates underlie learning to inhibit fear responses in extinction and re-learning to inhibit these responses in re-extinction. The amygdala is critical for learning to inhibit fear in extinction, but re-learning this inhibition can occur when neuronal activity in the amygdala is disrupted. Rats subjected to two conditioning episodes and then extinguished under a drug that disrupts neuronal activity in the amygdala (e.g., the $N$-methyl D-aspartate [NMDA] receptor antagonist, DL-APV, the local anesthetic, bupivicaine, or the $\mathrm{GABA}_{\mathrm{A}}$ agonist, muscimol) show relatively few fear responses across extinction, but substantial levels of fear responses on a subsequent retention test in comparison to the low levels of fear responses on the test by control rats extinguished under vehicle. In contrast, rats that received initial extinction between the two conditioning episodes, and then re-extinction under each of these drugs show few fear responses not only across re-extinction, but also on the subsequent retention test (Kim and Richardson 2008; Laurent and Westbrook 2008; Laurent et al. 2008). These results suggest that rats must show fear (i.e., there is activity in amygdala-based fear circuits) in order to learn to inhibit fear, but do not have to show fear (i.e., activity in the amygdala circuits is depressed) in order to re-learn this inhibition. Just as danger reinstates fear to an extinguished CS, the absence of fear across re-extinction may re-activate and strengthen the original inhibitory memory. Essentially, the absence of fear disambiguates the "meaning" of the CS, converting it from one that is dangerous to one that is again safe.

Anxiolytic drugs, such as benzodiazepines, also reduce fear and anxiety in both people and animal subjects. This reduction in fear and anxiety is likely due to the action of the drug at the $\mathrm{GABA}_{\mathrm{A}}$ receptor site in the amygdala. For example, infusion of a benzodiazepine into the amygdala reduces fear responses in rats (Helmstetter 1993; Harris and Westbrook 1995), while infusion of an antagonist increases anxiogenic responses (Sanders and Shekhar 1991). In previous work, Hart et al. (2009) reported that the administration of a benzodiazepine (midazolam) prior to extinction impaired long-term inhibitory learning, but that administration of the drug prior to re-extinction failed to produce this impairment. That is, rats given a benzodiazepine before re-extinction showed low levels of fear responding on a subsequent retention test. These levels of freezing were equivalent to those by control rats re-extinguished or extinguished under vehicle and were substantially lower than those by rats that received their initial extinction under the drug. These results were obtained using a context or a discrete stimulus as the fear CS and when the drug was administered systemically or directly into the amygdala. Moreover, the drug only spared re-learning to inhibit fear responses across re-extinction if there had been initial learning of that inhibition: The drug impaired re-extinction in rats that had received their initial extinction under the drug. Thus, as in the case of manipulations that depress neuronal activity in the amygdala-based fear circuits, we proposed that the anxiolytic effects of the drug across re-extinction restores the subjects to the state (no fear) produced by extinction, thereby activating and strengthening the original inhibition that underlies the longterm suppression of fear observed on the retention test.

The present experiments provided a further examination of the effects of midazolam on learning and re-learning to inhibit fear responses. The aim was to determine whether the drug not only spares, but even facilitates, re-learning to inhibit fear responses. Facilitation could occur because the drug reduces or eliminates entirely the fear responses that nondrugged subjects must re-learn to inhibit. Hence, the drug may short-circuit the processes required to inhibit the fear responses restored by reconditioning because the absence of fear activates the original inhibitory memory, which is then strengthened across re-extinction. The present experiments studied this suggestion by asking whether the drug could support re-learning in rats that received relatively short durations of extinction or re-extinction. Rats received two cycles of context fear conditioning and extinction (i.e., conditioning and extinction followed by reconditioning and re-extinction), or two context-conditioning episodes followed by initial extinction (i.e., there was no extinction session between the two conditioning episodes). A subsequent drugfree retention test (conducted $24 \mathrm{~h}$ after re-extinction or the initial extinction) assessed the long-term inhibition of fear responses produced by extinction or re-extinction. Experiment 1 subjected rats to a 20-min extinction session and then examined the duration of re-extinction (4 $\mathrm{min}$ or $20 \mathrm{~min}$ ) required for re-learning inhibition under systemically injected drug or vehicle. Experiment 2 examined the duration of extinction (4 min or $20 \mathrm{~min}$ ) required for long-term inhibition and the effects of systemically injected drug or vehicle on this learning. In Experiment 3, rats received 20-min re-extinction under systemically injected drug when their initial extinction had been 5,10 , or $20 \mathrm{~min}$ or when there had been no extinction. In Experiment 4, rats received 5-, 10-, or 20-min re-extinction under systemically injected drug when the initial extinction had been $5 \mathrm{~min}$. Experiment 5 subjected rats to a 20 -min extinction session and then to 4 - or 20-min re-extinction under midazolam or vehicle infused into the basolateral amygdala (BLA).

\section{Results}

\section{Experiment 1}

Four groups of rats were used $(n=8)$. A summary of the design of this and the remaining experiments is shown Table 1. All groups received context conditioning on Day 1 . On Day 2, all rats received 20-min context extinction. On Day 3, all rats received a second context-conditioning episode. On Day 4, rats received either 4-min (Groups 4min) or 20-min (Groups 20min) re-extinction. Ten minutes before this second extinction session, half of the rats in each group received an intraperitoneal (ip) injection of vehicle (Groups Re-Ext 4min VEH and Re-Ext 20min VEH), while the remaining rats in each group received midazolam (Groups Re-Ext 4min MID and Re-Ext 20min MID). Two hours after extinction, vehicle rats were injected with the drug, while the midazolam rats were injected with vehicle. These injections occurred in the colony room. Counterbalancing of drug and vehicle was done to ensure that any effects on the subsequent test levels of responding in the midazolam rats were due to re-extinction under the drug rather than to the drug per se. On Day 5, all rats were tested drug-free for 10 min under extinction.

Figure 1 shows the mean and standard error of the mean (SEM) levels of freezing across extinction on Day 2 (panel A), across the 4- or 20-min re-extinction session on Day 4 (panel B), and across test on Day 5 (panel C). Conditioning on Day 1 was successful: All rats showed post-shock freezing indicative of context conditioning (Fanselow 1980) and substantial levels of freezing on Day 2. These levels declined across extinction and there were no significant differences between the groups $\left(F_{\mathrm{s}}<4.0: F_{\mathrm{c}(1,28)}\right.$ $d f=6.5)$. Re-conditioning on Day 3 restored fear responses, and there were no significant differences between groups in their levels of post-shock freezing $\left(F_{\mathrm{s}}<1.0\right)$. On Day 4 , rats that received 4-min re-extinction under midazolam (Group Re-Ext $4 \mathrm{~min}$ MID) froze more and/or were more immobile than rats 
Table 1. Designs of Experiments 1-5

Experiment 1 (ip) and Experiment 5 (intra-BLA)

\begin{tabular}{|c|c|c|c|c|c|}
\hline Group & Day 1 & Day 2 & Day 3 & Day 4 & $\begin{array}{l}\text { Day } 5 \\
\text { (test) }\end{array}$ \\
\hline $\begin{array}{l}\text { Re-Ext } 20 \text { min VEH } \\
\text { Re-Ext } 20 \text { min MID } \\
\text { Re-Ext } 4 \text { min VEH } \\
\text { Re-Ext } 4 \text { min MID }\end{array}$ & $\begin{array}{l}C x+ \\
C x+ \\
C x+ \\
C x+\end{array}$ & $\begin{array}{l}20 \min C x- \\
20 \min C x- \\
20 \min C x- \\
20 \min C x-\end{array}$ & $\begin{array}{l}C x+ \\
C x+ \\
C x+ \\
C x+\end{array}$ & $\begin{array}{r}20 \min C x-(V E H) \\
20 \min C x-(M I D) \\
4 \min C x-(V E H) \\
4 \min C x-(M I D)\end{array}$ & $\begin{array}{l}C x- \\
C x- \\
C x- \\
C x-\end{array}$ \\
\hline \multicolumn{6}{|c|}{ Experiment 2} \\
\hline $\begin{array}{l}\text { Ext } 20 \text { min VEH } \\
\text { Ext } 20 \text { min MID } \\
\text { Ext } 4 \text { min VEH } \\
\text { Ext } 4 \text { min MID }\end{array}$ & $\begin{array}{l}C x+ \\
C x+ \\
C x+ \\
C x+\end{array}$ & $\begin{array}{l}\text { handle } \\
\text { handle } \\
\text { handle } \\
\text { handle }\end{array}$ & $\begin{array}{l}C x+ \\
C x+ \\
C x+ \\
C x+\end{array}$ & $\begin{array}{r}20 \min C x-(\mathrm{VEH}) \\
20 \min C x-(\mathrm{MID}) \\
4 \min C x-(\mathrm{VEH}) \\
4 \min C x-(\mathrm{MID})\end{array}$ & $\begin{array}{l}C x- \\
C x- \\
C x- \\
C x-\end{array}$ \\
\hline \multicolumn{6}{|c|}{ Experiment 3} \\
\hline $\begin{array}{l}\text { Ext } 0 \mathrm{~min} \\
\text { Ext } 5 \mathrm{~min} \\
\text { Ext } 10 \mathrm{~min} \\
\text { Ext } 20 \mathrm{~min}\end{array}$ & $\begin{array}{l}C x+ \\
C x+ \\
C x+ \\
C x+\end{array}$ & $\begin{array}{c}\text { handle } \\
5 \text { min } C x- \\
10 \min C x- \\
20 \min C x-\end{array}$ & $\begin{array}{l}C x+ \\
C x+ \\
C x+ \\
C x+\end{array}$ & $\begin{array}{l}20 \min C x-(M I D) \\
20 \min C x-(M I D) \\
20 \min C x-(M I D) \\
20 \min C x-(M I D)\end{array}$ & $\begin{array}{l}C x- \\
C x- \\
C x- \\
C x-\end{array}$ \\
\hline \multicolumn{6}{|c|}{ Experiment 4} \\
\hline $\begin{array}{l}\text { Re-Ext } 0 \text { min } \\
\text { Re-Ext } 5 \text { min } \\
\text { Re-Ext } 10 \mathrm{~min} \\
\text { Re-Ext } 20 \text { min }\end{array}$ & $\begin{array}{l}C x+ \\
C x+ \\
C x+ \\
C x+\end{array}$ & $\begin{array}{l}5 \min C x- \\
5 \min C x- \\
5 \min C x- \\
5 \min C x-\end{array}$ & $\begin{array}{l}C x+ \\
C x+ \\
C x+ \\
C x+\end{array}$ & $\begin{array}{c}\text { handle (MID) } \\
5 \text { min Cx - (MID) } \\
10 \min C x-(M I D) \\
20 \min C x-(M I D)\end{array}$ & $\begin{array}{l}C x- \\
C x- \\
C x- \\
C x-\end{array}$ \\
\hline
\end{tabular}

Rats were placed in a context $(\mathrm{Cx})$ where they were shocked $(+)$ and where fear was extinguished $(-)$. Rats were injected ip with midazolam (MID) or its vehicle (VEH) before brief (4 min) or long (20 min) re-extinction (Experiment 1) or extinction (Experiment 2) on Day 4. In Experiment 3, rats were extinguished on Day 2 for 5, 10, or 20 min or received control handling (handle), and were extinguished for 20 min under ip midazolam on Day 4. In Experiment 4, rats were extinguished for 5 min on Day 2, and received 5-, 10-, or 20-min extinction under ip midazolam, or control handling on Day 4. Experiment 5 was the same as Experiment 1 except that rats were infused into the BLA with midazolam or vehicle before re-extinction.

that received 4 min re-extinction under vehicle (Groups Re-Ext $4 \mathrm{~min} \mathrm{VEH})\left(F=7.8: F_{\mathrm{c}(1,14)} d f=4.6\right)$. Likewise, rats that received 20-min re-extinction under midazolam (Group Re-Ext 20min MID) froze more and/or were more immobile than rats that received 20-min re-extinction under vehicle (Groups Re-Ext 20min VEH) $\left(F=17.5: F_{\mathrm{c}(1,14)} d f=4.6\right)$. There was a significant group $\times$ trend interaction for the 20 -min groups $(F=6.6)$, indicating that overall levels of freezing decreased more rapidly across re-extinction for the vehicle group than for the midazolam group. In fact, there was little or no decline in responses among the drugged rats suggesting that the drug had produced sedation rather than freezing.

On test (Fig. 1C), rats that received 4-min re-extinction under midazolam exhibited low levels of freezing similar to rats that received 20-min re-extinction under either vehicle or midazolam. In contrast, rats that received 4-min re-extinction under vehicle showed substantially higher levels of freezing. Statistical analysis confirmed that rats in Group Re-Ext 4min VEH froze significantly more than those in Groups Re-Ext 20min VEH, Re-Ext 20min MID, and Re-Ext 4min MID $\left(F=12.2: F_{\mathrm{c}(1,28)} d f=6.5\right)$, and that there were no significant differences in the levels of freezing among rats in Groups Re-Ext 20min MID, Re-Ext 4min MID, and Re-Ext 20min VEH $\left(F_{\mathrm{s}}<1.0\right)$. There was a significant linear trend across the test $(F=18.2)$, indicating that averaged levels of freezing declined across the test session. However, there were no significant interactions between the contrasts testing for linear trend and the differences between groups, $\left(F=3.1: F_{\mathrm{c}(1,28)}\right.$ $d f=6.5$ ), indicating that differences in freezing persisted across the test.

\section{Experiment 2}

Experiment 1 replicated the previous findings of Hart et al. (2009) that rats re-extinguished for $20 \mathrm{~min}$ under midazolam (Group Re-Ext 20min MID) failed to show impairment on the subsequent retention test, exhibiting low levels of fear similar to those shown by rats reextinguished for $20 \mathrm{~min}$ under vehicle (Group Re-Ext 20min VEH). Experiment 1 revealed a novel finding: Rats reextinguished for just 4 min under midazolam (Group Re-Ext 4min MID) also showed low levels of fear on the retention test, suggesting that long-term inhibition had been just as effective with a short, as with a longer, re-extinction session. In contrast to the failure to detect an effect of the duration of re-extinction in the drug-treated rats, there was such an effect in vehicle-treated rats: Vehicle-treated rats re-extinguished for $4 \mathrm{~min}$ (Group Re-Ext $4 \mathrm{~min} \mathrm{VEH}$ ) froze significantly more at test than the other three groups, including the vehicle-treated rats re-extinguished for $20 \mathrm{~min}$ (Group Re-Ext 20min VEH). Experiment 2 examined the role of the initial extinction in producing this difference on the retention test between rats given 4-min re-extinction under drug or vehicle. The design (see Table 1) consisted in subjecting rats to two context conditioning episodes, a brief (4 min) or longer $(20 \mathrm{~min})$ extinction under the drug or vehicle, and finally, a retention test. Hart et al. (2009) have shown that rats given 20-min extinction under midazolam exhibited substantial levels of fear responses on the subsequent retention test, suggesting that the drug had disrupted learning inhibition. But we have not previously examined whether rats subjected to a shorter (e.g., $4 \mathrm{~min}$ ) extinction under the drug also show substantial levels of fear responses on the subsequent test. Of course, there is little reason to expect that short (4 min) extinction under the drug would lead to the development of learned inhibition when the longer (20 min) extinction had impaired this learning. But there is another possibility that can also explain the long-term effect when rats received a brief $(4 \mathrm{~min})$ re-extinction in the previous experiment. This possibility is that a brief extinction or re-extinction under the drug disrupts reconsolidation of the original fear memory, leading to low levels of fear responses on the subsequent test (for discussion, see Bustos et al. 2006, 2009). If this explanation is correct, then brief extinction under midazolam should disrupt reconsolidation of the conditioning memory and lead to low levels of fear responding at test.

Four groups of rats $(n=8)$ received context conditioning on Days 1 and 3. On Day 4, rats received either 4-min (Groups 4min) or 20-min (Groups 20min) extinction. This occurred $10 \mathrm{~min}$ after ip injection of vehicle for half of the rats in each group (Groups Ext 4min VEH and Ext 20min VEH) and midazolam for the remaining rats in each group (Groups Ext 4min MID and Ext 20min MID). Two hours after extinction, rats were given counterbalanced injections as in Experiment 1. On Day 5, all rats were tested for $10 \mathrm{~min}$ in the context under extinction.

Figure 2 shows the levels of freezing across extinction on Day 4 (Fig. 2A), and test on Day 5 (Fig. 2B). Conditioning on Days 

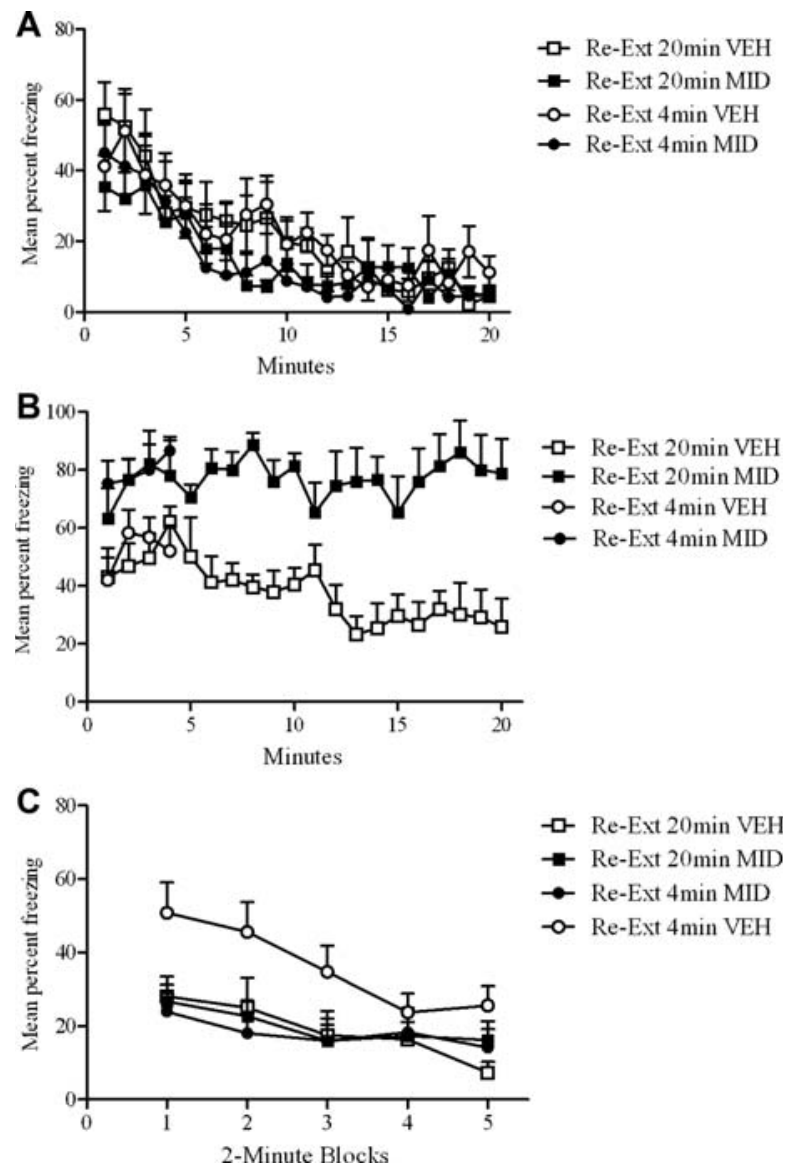

Figure 1. Mean percent (+ SEM) freezing in the conditioned context across extinction $(A)$, re-extinction $(B)$, and test $(C)$ for rats in each of the groups in Experiment 1. Context conditioning on Day 1 was followed by extinction on Day 2. Context conditioning on Day 3 was followed by either brief (4 $\mathrm{min}$ ) or long (20 $\mathrm{min}$ ) re-extinction under either midazolam (Groups Re-Ext 4min MID and Re-Ext 20min MID) or vehicle (Groups Re-Ext 4min VEH and Re-Ext 20min VEH) on Day 4. A drug-free retention test was on Day 5.

1 and 3 was successful: All rats showed post-shock freezing and there were no significant differences between groups $\left(F_{\mathrm{s}}<1.0\right.$ : $\left.F_{\mathrm{c}(1,28)} d f=6.5\right)$. Rats that received 4-min extinction under midazolam (Group Ext 4min MID) froze more and/or were more immobile than rats that received $4 \mathrm{~min}$ extinction after injection of vehicle (Groups Ext 4min VEH) $\left(F=13.2: F_{\mathrm{c}(1,14)} d f=4.6\right)$. Likewise, rats that received 20-min extinction under midazolam (Group Ext 20min MID) froze more and/or were more immobile than rats that received 20 min extinction after injection of vehicle (Groups Ext 20min VEH) $\left(F=28.2: F_{\mathrm{c}(1,14)} d f=4.6\right)$. There was a significant linear trend across extinction for rats in the 20-min groups $(F=5.0)$, indicating that levels of freezing significantly decreased across the extinction session.

Test data (Fig. 2B) show that vehicle-treated rats given 20-min extinction exhibited the least fear, freezing significantly less than midazolam-treated rats given 20-min extinction and rats given 4-min extinction after either vehicle or midazolam injection $\left(F=7.8: F_{\mathrm{c}(1,28)} d f=6.5\right)$. There were no significant differences between the levels of freezing among rats in Groups Ext 20min MID, Ext 4min MID, and Ext 4min VEH $\left(F_{\mathrm{s}}<1.0\right)$. Inspection of the data across test indicates that Group Ext 20min $\mathrm{VEH}$ entered test with lower levels of fear responding than the other three groups and that these levels declined across test for all groups. This inference was confirmed by a significant linear trend, as averaged across all groups $(F=17)$ and a nonsignificant group $\times$ trend interaction $(F<1.0)$ indicating that the differences present at the start of test persisted across the entire session. Thus, the longer extinction under vehicle produced better long-term inhibition than did the short interval under vehicle, the longer extinction session under the drug, or, critically, the short extinction under the drug.

However, inspection of Figure 2B suggests that rats subjected to a brief extinction under the drug may have reduced fear responses across the final $4 \mathrm{~min}$ of test more rapidly than did rats that received the brief extinction under vehicle or the longer extinction under drug. The contrast testing for the interaction between linear trend and the differences between Group Ext $4 \mathrm{~min}$ MID vs. Groups Ext $4 \mathrm{~min}$ VEH and Ext 20min MID approached, but did not reach, a conventional level of significance $\left(F=5.9: F_{\mathrm{c}(1,28)} d f=6.5\right)$. Post-hoc tests using the technique developed by Scheffé (1959) of the freezing levels across the final 4 min of test failed to reveal statistically significant differences between Group Ext $4 \mathrm{~min}$ MID vs. Groups Ext $4 \mathrm{~min}$ VEH and Ext 20min MID $(F=4.2)$ or between Group Ext 4min MID and either Group Ext $4 \mathrm{~min}$ VEH $(F=3.6)$ or Group Ext 20min MID $\left(F=2.8: F_{\mathrm{c}(3,28)} d f=8.8\right)$. Therefore, in contrast to the results obtained when rats were re-extinguished under the drug, the present results show that rats subjected to a shorter or longer extinction under the drug were impaired in developing long-term inhibition of fear. Taken together, the results of these experiments show that the long-term effect of brief re-extinction under the drug was not due to disruption in reconsolidation of the original fear memory produced by conditioning. Rather, these results suggest that the long-term effect of brief re-extinction under the drug involved activation and strengthening of the original inhibition produced by extinction.

\section{Experiment 3}

The results of the previous experiments show that midazolam impaired learning to inhibit fear responses in extinction but did
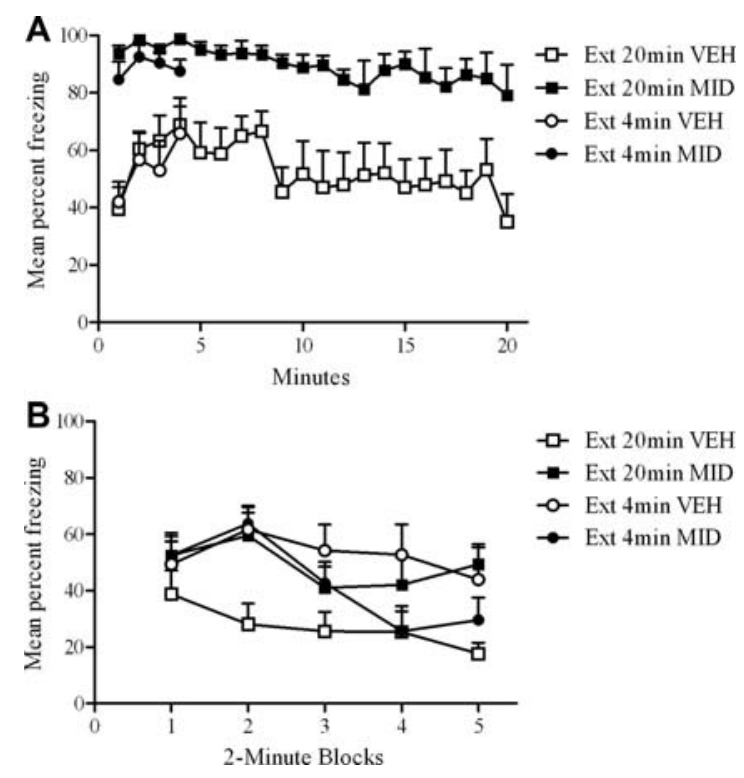

Figure 2. Mean percent (+ SEM) freezing in the conditioned context across extinction $(A)$ and test $(B)$ for rats in each of the groups in Experiment 2. Context conditioning on Days 1 and 3 was followed by either brief (4 $\mathrm{min})$ or long (20 $\mathrm{min}$ ) extinction under either midazolam (Groups Ext 4min MID and Ext 20min MID) or vehicle (Groups Ext 4min VEH and Ext 20min VEH) on Day 4. A drug-free retention test was on Day 5. 
not impair and even facilitated re-learning inhibition in the second extinction. Experiment 3 examined how much initial learning of inhibition was necessary for re-learning inhibition under drug. The design (see Table 1) consisted in subjecting rats to an initial extinction, which was 5,10 , or $20 \mathrm{~min}$ in duration and then subjecting all rats to a 20 -min re-extinction session under midazolam. Control rats were treated identically except the initial extinction was omitted. Based on the previous results, rats subjected to an initial 20-min extinction session and re-extinguished under the drug will show less fear responses on the retention test than control rats not receiving the initial extinction. The question of interest, however, was whether initial extinction lasting 5 or $10 \mathrm{~min}$ would be sufficient to protect against the midazolaminduced impairment expected in the rats given no initial extinction.

All rats received context conditioning on Day 1. On Day 2 the rats were allocated to four groups $(n=8)$ matched for their post-shock levels of freezing. Rats in Groups Ext 5min, Ext $10 \mathrm{~min}$, and Ext 20min received a 5-, 10-, or 20-min extinction session, respectively. Rats in Group Ext 0min received control handling. On Day 3, all rats received a second contextconditioning episode. On Day 4 , all rats received 20 min extinction under midazolam, administered ip $10 \mathrm{~min}$ prior to the onset of extinction. On Day 5, all rats were tested for $10 \mathrm{~min}$ in the context under extinction.

Figure 3 shows the levels of freezing across extinction on Day 2 (Fig. 3A), extinction/re-extinction on Day 4 (Fig. 3B), and test on Day 5 (Fig. 3C). Conditioning on Day 1 was successful as all rats showed post-shock freezing and there were no statistically significant differences between the groups, $F_{\mathrm{s}}<3$.0. Rats in Groups Ext $5 \mathrm{~min}$, Ext $10 \mathrm{~min}$, and Ext 20min showed substantial levels of freezing on Day 2. These levels declined across extinction and there did not appear to be any differences in the rate of this decline between the groups. Rats in Groups 5, 10, and 20 min did not show any significant differences in their levels of freezing across the first $5 \mathrm{~min}$ of extinction $\left(F<1.5: F_{\mathrm{c}(1,21)} d f=5.8\right)$. There were also no significant differences between rats in Groups Ext 10min and Ext 20min across the first $10 \mathrm{~min}$ of extinction $\left(F<1.0: F_{\mathrm{c}(1,14)} d f=4.6\right)$. There was a significant linear trend $(F=5.4)$, indicating that freezing significantly decreased across the first $10 \mathrm{~min}$ of extinction, and there were no differences between the two groups in their rate of decline $(F<1.0)$. Rats in Groups 5, 10, and 20 min entered reconditioning on Day 3 with significantly lower fear levels in the pre-shock period than those in Group Ext Omin $\left(F=18.4: F_{\mathrm{c}(1,28)} d f=6.5\right)$. Fear responses were restored by reconditioning, and there were no significant differences between groups in post-shock levels of freezing $\left(F_{\mathrm{s}}<2.0\right)$. All groups showed similar high levels of freezing and/or immobility across extinction/re-extinction on Day 4 under the systemically administered drug, and there were no statistically significant differences between groups $\left(F_{\mathrm{s}}<4.5, F_{\mathrm{c}(1,28)} d f=6.5\right)$.

Test data (Fig. 3C) show that rats that received no initial extinction on Day 2 followed by extinction under midazolam on Day 4 (Group Ext 0min) froze more than rats that received 5-, 10-, or 20-min initial extinction. Statistical analysis confirmed that rats in Groups Ext Omin froze significantly more than those in Groups Ext 5min, Ext 10min, and Ext 20min $\left(F=19.6: F_{\mathrm{c}(1,28)}\right.$ $d f=6.5)$. There were no significant differences between the levels of freezing among rats in Groups Ext $5 \mathrm{~min}$, Ext 10min, and Ext $20 \mathrm{~min}\left(F_{\mathrm{s}}<1.0\right)$, showing that a relatively brief ( $5 \mathrm{~min}$ ) initial extinction was sufficient for rats to re-learn inhibition under the drug. There was a statistically significant linear trend $(F=21.8)$, indicating that levels of fear responding declined across the test. The group $\times$ trend interaction did not reach significance $(F=2.5)$ indicating that the differences between Group Ext Omin and the other three groups persisted across test.
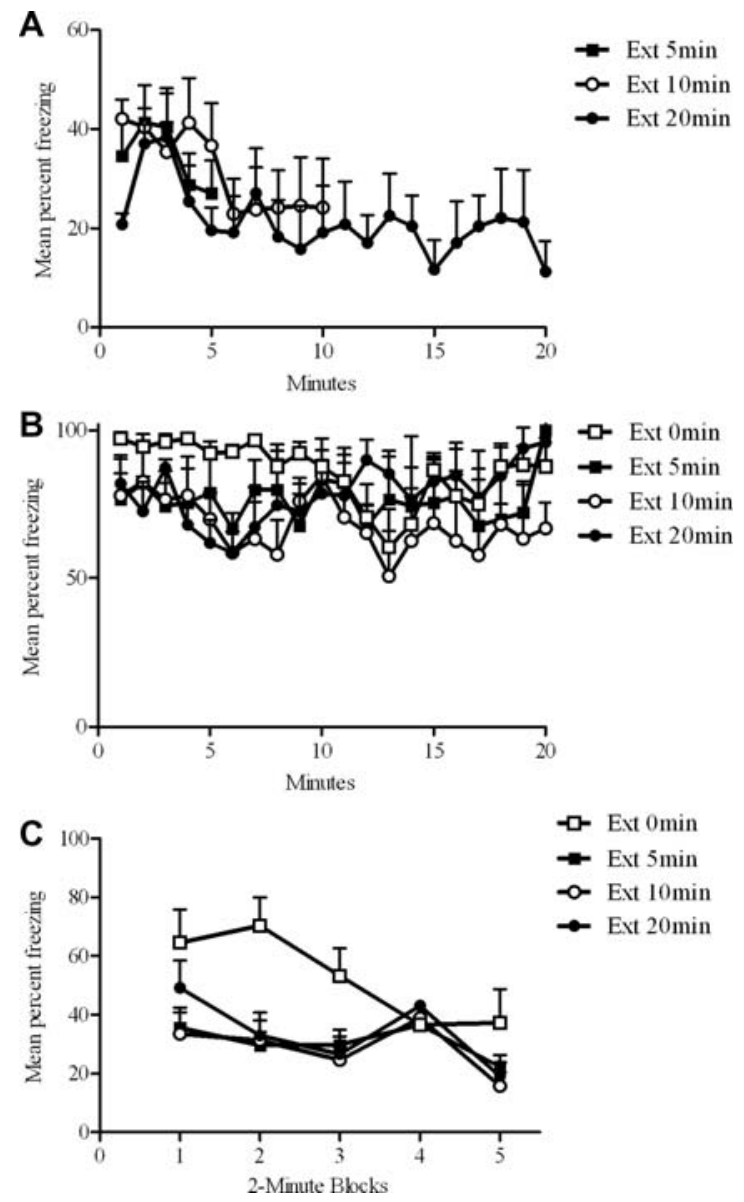

Figure 3. Mean percent ( + SEM) freezing in the conditioned context across extinction $(A)$, extinction/re-extinction $(B)$, and test $(C)$ for rats in each of the groups in Experiment 3. Context conditioning on Day 1 was followed by 5 -min (Group Ext $5 \mathrm{~min}$ ), 10 -min (Group Ext 10min), or 20-min (Group Ext 20min) extinction on Day 2. Rats in Group Ext 0 min received control handling. Context conditioning on Day 3 was followed by 20-min re-extinction under midazolam for all groups on Day 4. A drug-free retention test was on Day 5.

\section{Experiment 4}

Experiment 3 demonstrated that as little as 5-min initial extinction was sufficient to provide protection against impairment across 20-min subsequent extinction under midazolam. The present experiment examined how much re-extinction under midazolam is sufficient to produce re-learning of inhibition by rats subjected to a short $(5 \mathrm{~min})$ initial extinction. The design (see Table 1) consisted in subjecting rats to 5-min initial extinction and 5-, 10-, or 20-min re-extinction under midazolam. Control rats received the initial 5-min extinction, but did not receive re-extinction. This was done to assess the effect of the 5-min extinction session between the two context conditioning episodes on the test levels of freezing. These control rats should freeze more on test than rats receiving 20-min re-extinction under the drug. The question of interest was whether 5- or 10-min re-extinction under the drug was sufficient to produce re-learning when the duration of the initial extinction had been $5 \mathrm{~min}$.

Four groups of rats $(n=8)$ received context conditioning on Day 1 and 5-min extinction on Day 2. On Day 3, all rats received a second context-conditioning episode. On Day 4, rats in Groups Re-Ext $5 \mathrm{~min}$, Re-Ext $10 \mathrm{~min}$, and Re-Ext $20 \mathrm{~min}$ received 5 , 10, or $20 \mathrm{~min}$ of re-extinction, respectively, under midazolam, which 
was administered ip 10 min prior to the onset of extinction. Rats in Group Re-Ext Omin were injected with the drug, but did not receive extinction. On Day 5, all rats were tested for $10 \mathrm{~min}$ in the context under extinction.

Figure 4 shows the levels of freezing across extinction on Day 2 (Fig. 4A), re-extinction on Day 4 (Fig. 4B), and test on Day 5 (Fig. $4 \mathrm{C}$ ). Conditioning on Day 1 was successful as all rats showed postshock freezing, and there were no differences between groups $\left(F_{\mathrm{s}}<1.0: F_{\mathrm{c}(1,28)} d f=6.5\right)$. All rats showed substantial levels of freezing on Day 2. These levels significantly decreased across the 5 -min extinction session $(F=15.2)$, and there were no significant differences between groups $\left(F_{\mathrm{s}}<1.0\right)$. Conditioning was successful on Day 3. All rats showed substantial levels of post-shock freezing and there were no significant differences between groups in the levels of post-shock freezing $\left(F_{\mathrm{s}}<1.0\right)$. Groups 5,10 , and 20 min showed similar high levels of freezing and/or immobility across the entire re-extinction session, and there were no differences between either Groups 5, 10, and $20 \mathrm{~min}$ across the first 5 min of re-extinction or between Groups 10 and 20 min across the first $10 \mathrm{~min}$ of re-extinction $\left(F_{\mathrm{s}}<1.0\right)$.

Test data (Fig. 4C) show that rats that received 5-min initial extinction followed by no re-extinction (Group Re-Ext Omin) exhibited substantially higher levels of freezing than rats that
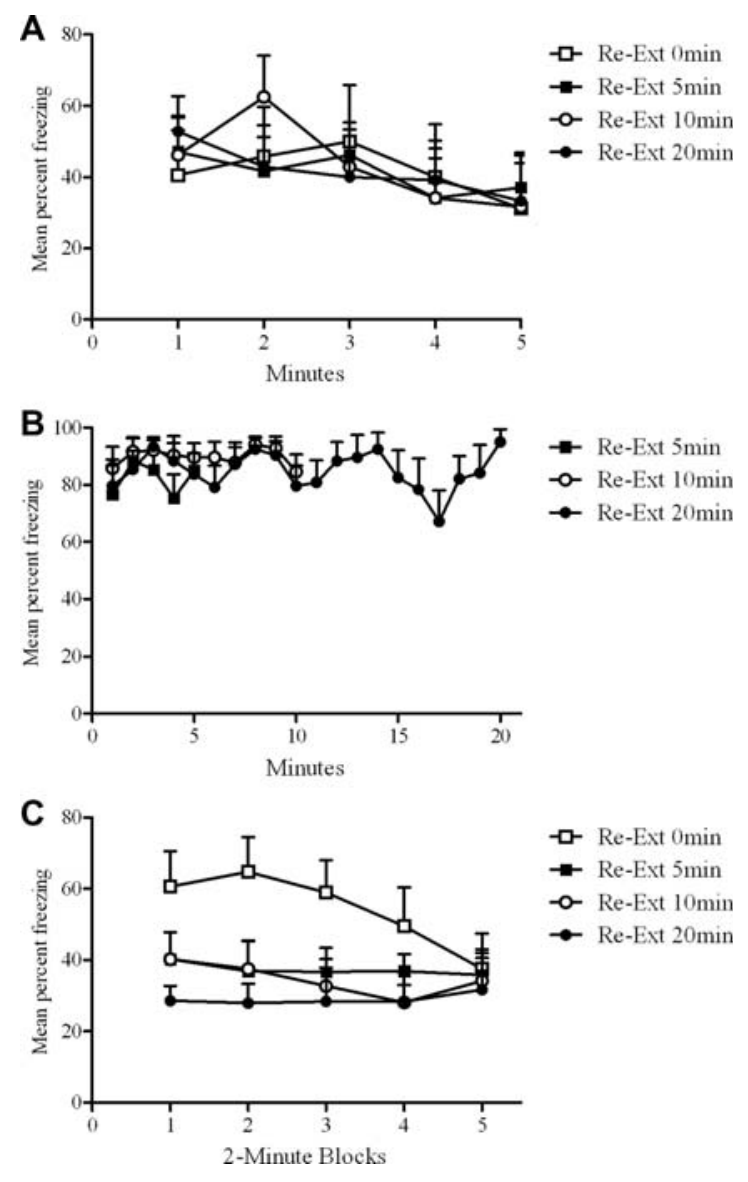

Figure 4. Mean percent $(+$ SEM) freezing in the conditioned context across extinction $(A)$, re-extinction $(B)$, and test $(C)$ for rats in each of the groups in Experiment 4. Context conditioning on Day 1 was followed by 5-min extinction on Day 2. Context conditioning on Day 3 was followed by 5-min (Group Re-Ext 5min), 10-min (Group Re-Ext 10min), or 20-min (Group Re-Ext 20min) re-extinction under midazolam on Day 4. Rats in Group Re-Ext Omin received control handling under midazolam. A drug-free retention test was on Day 5. received 5, 10, or 20 min re-extinction. Statistical analysis confirmed that rats in Groups Re-Ext Omin froze significantly more than those in Groups Re-Ext 5min, Re-Ext 10min, and Re-Ext $20 \mathrm{~min}\left(F=8.1: F_{\mathrm{c}(1,28)} d f=6.5\right)$. There were no significant differences between the levels of freezing among rats in Groups Re-Ext $5 \mathrm{~min}$, Re-Ext $10 \mathrm{~min}$, and Re-Ext $20 \mathrm{~min}\left(F_{\mathrm{s}}<1.0\right)$. Inspection of the data indicates that Group Re-Ext Omin entered test with higher levels of freezing than the other three groups. However, whereas the levels of freezing declined across test in Group Re-Ext Omin, there was little or no such decline in the remaining groups. Neither the contrast testing for linear trend was significant $(F=3.1)$ nor was the contrast testing for group $\times$ trend interaction $(F=3.7)$, which was likely due to the persistence of the difference between Group Re-Ext Omin and the other three groups for the majority of the test session. These results show that rats, given a relatively brief initial extinction, can re-learn the inhibition that mediates long-term suppression of fear when re-extinguished for as little as $5 \mathrm{~min}$ or as long as $20 \mathrm{~min}$ under the drug.

\section{Experiment 5}

The aim of this experiment was to determine whether the facilitation by midazolam of long-term inhibition in rats that received a short $(4 \mathrm{~min})$ re-extinction was due to the drug's action in the amygdala. The procedure was modified by pre-exposing rats for $8 \mathrm{~min}$ to the context prior to conditioning, and increasing the intensity of the shock US to ensure substantial fear conditioning. The design was that used in Experiment 1 (see Table 1), except that rats received an infusion of midazolam or vehicle into the BLA before either brief (Groups Re-Ext 4min MID and Re-Ext 4min VEH) or long (Groups Re-Ext 20min MID and Re-Ext 20min VEH) re-extinction. Figure 5 shows the location of the cannula tips for rats $(N=29)$ whose data were included in the statistical analysis.

Figure 6 shows the levels of freezing across extinction on Day 2 (Fig. 6A), across the 4- or 20-min re-extinction session on Day 4 (Fig. 6B), and averaged across test on Day 5 (Fig. 6C). Conditioning on Day 1 was successful: All rats showed post-shock freezing indicative of context conditioning and there were no significant between-group differences $\left(F_{\mathrm{s}}<1.0\right)$. There were substantial levels of freezing on Day 2. There was a significant linear trend $(F=$ 23.8: $\left.F_{\mathrm{c}(1,25)} d f=6.6\right)$, indicating that the levels of freezing declined across extinction, and there were no significant differences between the groups $\left(F_{\mathrm{s}}<3.5\right)$. Re-conditioning on Day 3 restored fear responses among all rats, and there were no significant differences between groups in their levels of post-shock freezing $\left(F_{\mathrm{s}}<3.0\right)$. On Day 4 , rats that received 4-min re-extinction under midazolam (Group Re-Ext $4 \min$ MID $n=8$ ) froze significantly less than rats that received 4 min re-extinction under vehicle (Groups Re-Ext $4 \mathrm{~min}$ VEH $n=7)\left(F=7.7: F_{\mathrm{c}(1,13)} d f=\right.$ 4.7). Likewise, rats that received 20 -min re-extinction under midazolam (Group Re-Ext 20min MID $n=7$ ) froze less than rats that received 20-min re-extinction under vehicle (Groups Re-Ext 20min VEH $n=7$ ), but this difference did not reach conventional levels of statistical significance $\left(F=3.2: F_{\mathrm{c}(1,12)} d f=4.7\right)$. Rats re-extinguished for $20 \mathrm{~min}$ under vehicle showed a reduced level of freezing at the end of extinction similar to the freezing/immobility by rats re-extinguished under the drug. However, the contrast testing for linear trend was not statistically significant, $(F=3.2)$, which, from the standard error, was due to the variability among the vehicle-treated rats in their freezing levels across re-extinction.

Test data (Fig. 6C) show that rats re-extinguished for $4 \mathrm{~min}$ under a BLA infusion of midazolam exhibited low levels of freezing similar to those by rats re-extinguished for $20 \mathrm{~min}$ under 


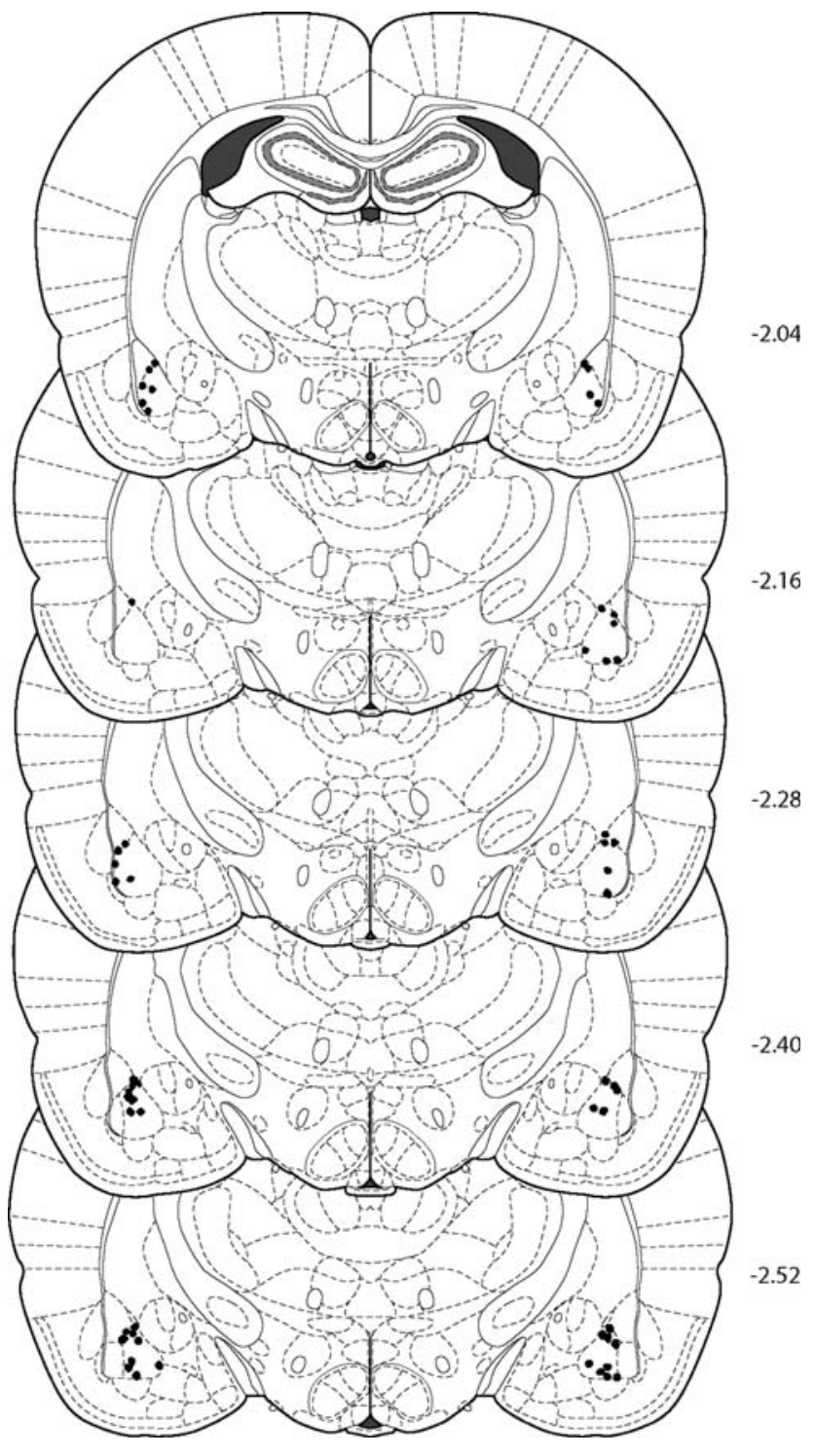

Figure 5. Cannula placement for rats in Experiment $5(N=29)$. $(\bullet)$ Represent the location of the cannula tips at five different rostral-caudal planes. The numbers represent the posterior coordinates (millimeters) from bregma.

either midazolam or vehicle. In contrast, rats re-extinguished for 4 min under vehicle showed substantially higher levels of freezing. Statistical analysis confirmed that rats in Group Re-Ext 4 min VEH froze significantly more than those in Groups Re-Ext 20min VEH, Re-Ext 20min MID, and Re-Ext 4min MID ( $F=7.7$ : $\left.F_{\mathrm{c}(1,25)} d f=6.6\right)$. There were no significant differences between the levels of freezing among rats in Groups Re-Ext 20min VEH, Re-Ext 20min MID, and Re-Ext 4min MID ( $\left.F_{\mathrm{s}}<1.0\right)$. Inspection of the data across test indicates that Group Re-Ext 4min MID came into test with substantially higher levels of fear responses than the other three groups and that these levels declined across test for all groups. There was a statistically significant linear trend $(F=23.2)$, but the group $\times$ trend interaction was not significant $(F<1.0)$, indicating that the difference between Group Re-Ext 4min MID and the other three groups persisted across test. These results, when the drug was infused into the BLA, replicated those obtained previously when the drug had been injected systemically. Thus, the BLA constitutes a site at which the drug impairs learning to inhibit fear responses, but facilitates re-learning this inhibition.

\section{Discussion}

These experiments have confirmed that systemic or intra-BLA infusion of midazolam before initial extinction impairs the learning that underlies the long-term inhibition of fear responses (Hart et al. 2009). For example, in Experiment 2, rats received two cycles of context conditioning followed by extinction and a retention test. The duration of extinction was longer $(20 \mathrm{~min})$ or shorter (4 min) and occurred under systemic injection of the drug or vehicle. The subsequent drug-free test revealed that rats that received the longer extinction under vehicle froze less than rats that received the shorter extinction under vehicle, showing that the duration of extinction determined the amount of long-term inhibition. Rats that received the longer extinction also froze less than rats subjected to either the long or the short extinction under midazolam, showing that the drug had impaired this learning regardless of the duration of extinction.

These experiments have also confirmed that systemic or intra-BLA infusion of midazolam spares re-learning to inhibit
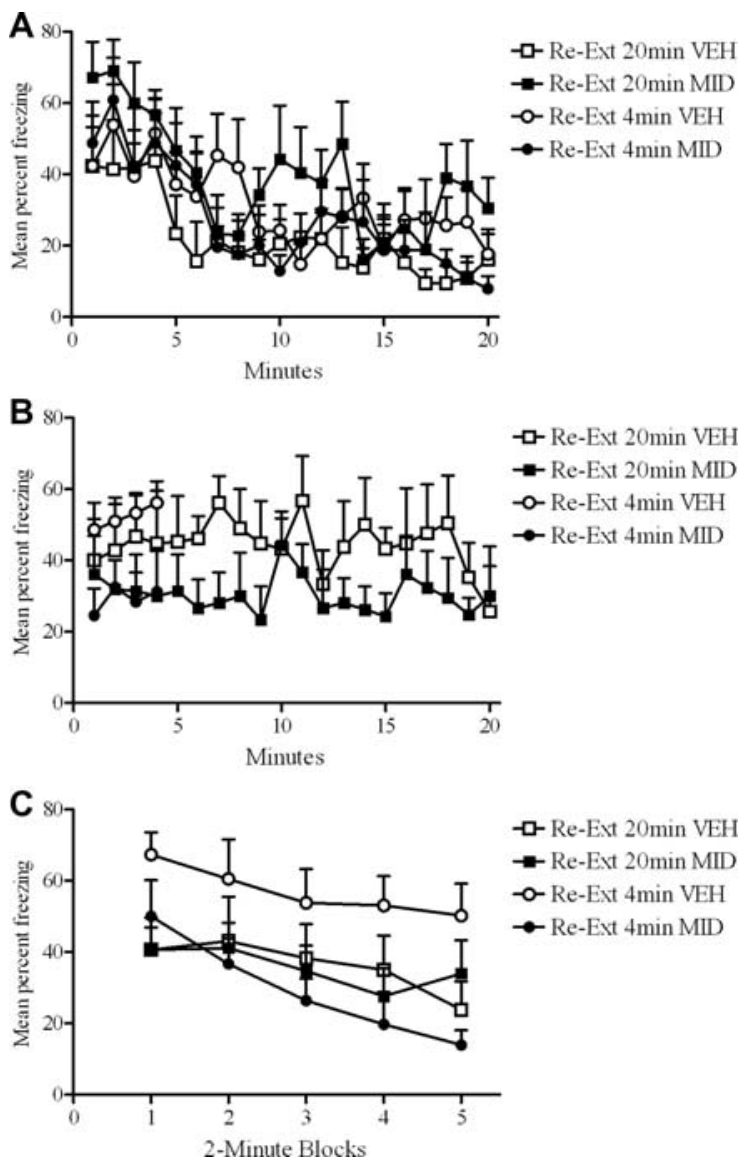

Figure 6. Mean percent $(+$ SEM) freezing in the conditioned context across extinction $(A)$, re-extinction $(B)$, and test $(C)$ for rats in each of the groups in Experiment 5. Context conditioning on Day 1 was followed by extinction on Day 2. Context conditioning on Day 3 was followed by either brief ( $4 \mathrm{~min}$ ) or long (20 $\mathrm{min}$ ) re-extinction under BLA infusion of either midazolam (Groups Re-Ext 4min MID and Re-Ext 20min MID) or vehicle (Groups Re-Ext 4min VEH and Re-Ext 20min VEH) on Day 4. A drug-free retention test was on Day 5. 
fear responses and revealed that such an infusion even facilitates this re-learning. Rats were subjected to two cycles of context conditioning and extinction followed by a retention test. In Experiments 1 and 5, the duration of the initial extinction was longer $(20 \mathrm{~min})$ and that of the second was either longer $(20 \mathrm{~min}$ ) or shorter (4 min). The second extinction occurred under a systemic (Experiment 1) or intra-BLA (Experiment 5) injection of drug or vehicle. In both experiments, the retention test showed that rats subjected to the shorter re-extinction under vehicle froze more than rats that received the longer re-extinction under either vehicle or drug, or, critically, rats that received the shorter re-extinction under drug. In Experiments 3 and 4, the second extinction also occurred under the drug; Experiment 3 varied the duration of the initial extinction $(5,10$, or $20 \mathrm{~min})$ while subjecting all rats to a longer ( $20 \mathrm{~min}$ ) re-extinction; Experiment 4 subjected rats to a fixed ( $5 \mathrm{~min}$ ) initial extinction, while varying the duration $(5,10$, or $20 \mathrm{~min})$ of the second extinction. In each experiment, rats that received the second extinction under the drug exhibited similar low levels of freezing on the retention test regardless of the duration of the initial or the second extinction. These levels were less than those shown by control rats that did not receive the initial extinction, but did receive the later 20-min extinction under the drug (Experiment 3 ) or by control rats that received the initial 5-min extinction, but did not receive the second extinction (Experiment 4).

Experiments 1-4 failed to find direct evidence for the anxiolytic effects of midazolam when administered systemically. Rather, rats given the drug remained immobile across the entire extinction/re-extinction session, suggesting that the drug had produced sedation. Sedation is a common product of systemic benzodiazepine administration, and has been reported to occur in both animals (Bouton et al. 1990; Harris and Westbrook 1998; Hart et al. 2009) and humans (Van Laar and Volkerts 1998). It is likely that the anxiolytic effects of the systemically administered drug were masked by sedation. Importantly, this sedation was absent in rats given an intra-BLA infusion of midazolam. In fact, these rats showed low levels of freezing across the entire re-extinction session, providing direct evidence for the anxiolytic properties of the drug. The absence of the sedative effects in rats that received the intra-BLA infusion may be explained in terms of subtype-specific effects of benzodiazepines on $\mathrm{GABA}_{\mathrm{A}}$ receptors. Recent evidence has suggested that the anxiolytic, but not the sedative effects of benzodiazepines may be mediated by $\alpha 2$ subtype of the $\mathrm{GABA}_{\mathrm{A}}$ receptor, whereas the sedative effects may be mediated by the $\alpha 1$ subtype. Specifically, a knock-in point mutation technique was used in two mouse lines, in which either the $\alpha 2$ or $\alpha 3 \mathrm{GABA}_{\mathrm{A}}$ receptors had been rendered insensitive to diazepam. It was found that the anxiolytic effects of diazepam were absent in the $\alpha 2$ knock-in mice, but not in the $\alpha 3$ mice (Low et al. 2000). This finding is consistent with existing evidence suggesting that the anxiolytic properties of the drug are mediated by the limbic system, which contains the majority of $\alpha 2 \mathrm{GABA}_{\mathrm{A}}$ receptors (Fritschy and Mohler 1995).

One explanation for the substantial test levels of freezing responses by rats extinguished under the drug is generalization decrement between training and test. For example, as noted in the introduction, inhibitory learning appears to be encoded against the cues present at extinction; leading to its activation when these cues are present and the renewal of fear responses in their absence (for discussion, see Bouton 1993). Hence, the substantial levels of fear responses at test for rats that received only one extinction session under the drug could be an example of renewal caused by the rats being tested in the absence of the drug-related cues present at extinction. In fact, there is evidence for such a renewal effect since rats extinguished and tested in the presence of a benzodiazepine show low levels of fear at test, consistent with retrieval of the extinction memory (Bouton et al. 1990). However, this renewal explanation should also apply to rats re-extinguished under the drug and tested in the absence of the drug-related cues. These rats, like those extinguished under the drug, should have been subject to renewal of fear responding on test. But this did not occur: Rats re-extinguished under the drug exhibited low levels of freezing responses on the drug-free retention test.

A second explanation for the substantial test levels of freezing responses by rats extinguished under the drug is in terms of error correction mechanisms. Contemporary models of associative learning invoke these mechanisms to explain a range of acquisition phenomena, such as blocking, contingency, and signal validity effects (for review, see Rescorla and Holland 1982). Such models also assume that the omission of the predicted shock US constitutes the error that drives the learning that underlies inhibition of fear responses in extinction: The greater the discrepancy between the levels of fear elicited by the CS and that appropriate (no fear) to the new contingency, the greater the amount of learned inhibition. According to this explanation, therefore, rats that enter extinction under a drug that depresses activity in amygdala-based fear circuits are subject to less of a discrepancy between their levels of fear and those appropriate to the absence of the US. Consequently, such rats acquire less of the learning that mediates long-term inhibition of fear responses. Consistent with this suggestion, rats extinguished under intra-amygdala administrations of a benzodiazepine, midazolam (Harris and Westbrook 1998; Hart et al. 2009), an anesthetic, bupivicaine (Kim and Richardson 2008), a $\mathrm{GABA}_{\mathrm{A}}$ agonist, muscimol, or the NMDA receptor antagonist, DL-APV (Laurent et al. 2008) exhibit low levels of fear responses across extinction, but substantial levels of such responses on a subsequent retention test. However, this error correction explanation should also apply to rats reextinguished under an intra-amygdala infusion of these drugs, but this does not occur. Rats re-extinguished under such drugs not only show low levels of fear across re-extinction, but also on the subsequent retention test.

Why is re-extinction not impaired when amygdala-based fear circuits are disrupted? One possible explanation is in terms of the contents of what is learned in extinction. As noted above, the contents of this learning have been viewed as an inhibitory CS-US or an excitatory CS-no US association activated by cues present across extinction. This learning converts the CS from one that is dangerous into one that is safe when such cues are present. By reducing activity in amygdala-based fear circuits across re-extinction, drugs, such as benzodiazepines, likewise convert the reconditioned CS from one that is dangerous, to one that is again safe. More specifically, the state of the rats across re-extinction under the drug is that produced by extinction (no fear). Hence, this state serves to activate the original inhibitory association across re-extinction, which is thereby strengthened or rendered more retrievable; leading to the low levels of fear on the retention test. The present results show that this reactivation and strengthening occurs independent of the duration of the re-extinction and of the duration of the initial extinction, at least across the durations used here.

Contemporary neuronal models of extinction invoke interactions among various structures, notably the amygdala and the infralimbic (IL) region of the medial prefrontal cortex (Likhtik et al. 2005; Quirk and Mueller 2008). Specifically, acquisition of inhibition in extinction involves the BLA, while its consolidation involves both the BLA and the IL and its subsequent retrieval requires the IL (Quirk and Mueller 2008; Laurent and Westbrook 2010). Inhibition appears to occur via NMDAr mediated changes in plasticity between projections from the BLA to a network of inhibitory interneurons in intercalated cells located between the 
BLA and central amygdala (CeA). These cells inhibit activation of the CeA, resulting in the suppression of fear responses (Pare and Smith 1993; McDonald 1998; Royer et al. 1999). Neurons in the BLA share reciprocal projections with the IL, which in turn, project to these intercalated cells. Once the extinction memory has been learned, it is this connection between the IL and these intercalated cells that allow it to exert its inhibitory effects on the CeA in the absence of a functioning BLA (Laurent and Westbrook 2008, 2009). Consistent with this model, disruption of neuronal activity in the BLA by infusion of midazolam impairs the longterm inhibition of fear responses produced by extinction. However, once the circuit between the IL and the intercalated cells has been established by extinction, it is activated and strengthened across re-extinction when neuronal activity in the BLA is disrupted by infusion of midazolam (Experiment 5). Further, the present results suggest that this activation and strengthening may occur across a shorter period of time (i.e., $4 \mathrm{~min}$ ) than that necessary for the initial establishment of inhibition. Thus, the establishment of this circuitry by initial extinction supported re-learning to inhibit fear responses across the second extinction of that context (Laurent and Westbrook 2009).

Finally, the present results may be relevant to some treatments of anxiety disorders in people. They confirm what has been shown in clinical trials, namely, that a combination of benzodiazepine and extinction-based therapies, such as cue exposure, will be less effective than cue exposure alone in promoting longterm inhibition of fear/anxiety responses (Birk 2004). They also suggest that following relapse, this combination may be more effective than cue exposure. Presumably, compliance by the patient when undergoing cue exposure in combination with the drug would also be increased.

\section{Materials and Methods}

\section{Subjects}

Subjects were 157 experimentally naïve male outbred Wistar rats (280-450 g; Rattus norvegicus) obtained from a colony of rats maintained by the Animal Resources Centre. Rats were housed in groups of four to eight in opaque plastic boxes $(67 \mathrm{~cm}$ deep $\times$ $40 \mathrm{~cm}$ wide $\times 22 \mathrm{~cm}$ high), which were kept in an air-conditioned colony room maintained on a 12:12 h light:dark cycle (lights on at 7:00 a.m.). All experiments were conducted during the light portion. Water and standard laboratory chow were continuously available. All experimental procedures were approved by the Animal Care and Ethics Committee at the University of New South Wales, and in accordance with the American Psychological Association guidelines for the treatment of animals in research.

\section{Drug}

In Experiments 1-4, midazolam (Hypnovel, Roche Products) was diluted in sterile isotonic saline $(0.9 \% \mathrm{w} / \mathrm{vol} \mathrm{NaCl})$ to a concentration of $1.25 \mathrm{mg} / \mathrm{mL}$. Midazolam or saline $(0.9 \% \mathrm{w} / \mathrm{vol} \mathrm{NaCl})$ was administered in a volume of $1.0 \mathrm{~mL} / \mathrm{kg}$ via intraperitoneal (ip) injection. Thus, the dose of midazolam was $1.25 \mathrm{mg} / \mathrm{kg}$. This dosage was chosen as one that has been previously used successfully (see Harris and Westbrook 1995, 1998, 1999, 2001; Hart et al. 2009).

In Experiment 5, midazolam diluted with saline was prepared to a concentration of $3.3 \mathrm{mg} / \mathrm{mL}$, and the $\mathrm{pH}$ adjusted to 5.0 by adding sodium hydroxide $(\mathrm{NaOH})$. A vehicle solution with the same $\mathrm{pH}$ was also prepared and $0.3 \mu \mathrm{L}$ of midazolam or vehicle solution was infused directly into the BLA across $3 \mathrm{~min}$. This dose and volume were those used previously by Hart et al. (2009).

\section{Surgery and infusion}

Rats were anaesthetized with $(100 \mathrm{mg} / \mathrm{mL})$ ketamine (Ketapex; Apex Laboratories), administered at a dose of $1.0 \mathrm{~mL} / \mathrm{kg}$ (ip), in combination with a muscle relaxant, xylazine $(20 \mathrm{mg} / \mathrm{mL})$ at a dosage of $0.3 \mathrm{~mL} / \mathrm{kg}$ (Rompun; Bayer).

The rat was placed in a stereotaxic apparatus (Kopf Instruments), and two 26-gauge guide cannulae (Plastics One) were implanted through holes drilled in both hemispheres of the skull. The tips of the guide cannulae were aimed bilaterally at the BLA located $2.35 \mathrm{~mm}$ posterior to bregma, $4.8-5 \mathrm{~mm}$ lateral to the midline, and 7.7-8 mm ventral to the skull. The guide cannulae were secured in position with dental cement attached to the skull by three jewelers' screws. A dummy cannula was kept in each guide at all times other than during infusions. Immediately after the surgical procedure, rats were injected ip with a prophylactic $(0.3 \mathrm{~mL})$ dose of $300 \mathrm{mg} / \mathrm{kg}$ solution of procaine penicillin. Rats were allowed $3 \mathrm{~d}$ to recover from surgery, during this time they were handled and weighed daily.

A solution of $0.3 \mu \mathrm{L}$ of midazolam or vehicle was infused bilaterally into the BLA through a 33-gauge internal cannula inserted into the guide cannula. The internal cannula was connected to a $25 \mu \mathrm{L}$ glass syringe attached to an infusion pump (Harvard Apparatus) and projected an additional $1 \mathrm{~mm}$ ventral to the tip of the guide cannula. A total volume of $0.3 \mu \mathrm{L}$ was delivered in both sides at a rate of $0.1 \mu \mathrm{L} / \mathrm{min}$. The internal cannulae were left in place for a further 1 min after the infusions to allow for diffusion. All rats were familiarized with this procedure on the day before infusion by removing the dummy cannulae and running the infusion pump for 3 min.

\section{Histology}

Upon completion of test, rats were overdosed with pentobarbital, decapitated, and their brains removed. A cryostat was used to slice brains into $40-\mu \mathrm{m}$ coronal sections. Every third section was collected on a slide and stained with cresyl violet. The locations of cannula tips were determined under a microscope by two trained observers using the boundaries defined by Paxinos and Watson (1998). Rats with inaccurate cannula placements or with extensive damage to the BLA were excluded from the statistical analysis.

\section{Apparatus}

The experiments took place in a set of four chambers $(23.5 \mathrm{~cm}$ deep $\times 20.5 \mathrm{~cm}$ wide $\times 19.5 \mathrm{~cm}$ high). The side walls were constructed of aluminum, while the end walls and lids were constructed of clear Perspex. The floor consisted of stainless steel bars, $2 \mathrm{~mm}$ in diameter, spaced $13 \mathrm{~mm}$ apart (center to center). Unscrambled AC $50 \mathrm{~Hz}$ shock from a constant current generator could be delivered to the floor of each chamber. The current available to each floor could be adjusted by reference to an in-line milliampere meter in order to compensate for any differences in the body weight of the rats. Below each floor was a tray containing bedding material. Upon removal of a rat, each chamber was cleaned with a paper towel moistened with a $1 \%$ acetic acid solution and the bedding changed. Each chamber was located in separate compartments of a wooden cabinet whose floor, ceiling, and walls were painted black. The room containing this cabinet was illuminated by four $40-\mathrm{W}$ incandescent light bulbs located on the ceiling, two of which were clear white and two red. The background noise level of the room was $50 \mathrm{~dB}$. The behavior of each rat was recorded using cameras mounted on the wall behind each compartment. The cameras were connected to a video recorder and monitor located in another room in the laboratory.

\section{Procedure}

\section{Experiment 1}

On Day 1, all rats were placed in the context for $1 \mathrm{~min}$, before receiving a $0.5-\mathrm{mA}, 1$-sec footshock. Rats remained in the chambers for a further $2 \mathrm{~min}$, before being removed and returned to their home cages. On Day 2 all rats received extinction training. 
This consisted of a 20-min nonreinforced exposure to the context. On Day 3, all rats received identical conditioning as on Day 1, and on Day 4, all rats received re-extinction training. Re-extinction training consisted of either a 4-min (Groups Re-Ext 4min MID and Re-Ext 4min VEH) or 20-min (Groups Re-Ext 20min MID and Re-Ext 20min VEH) nonreinforced exposure to the context. Ten minutes prior to the onset of re-extinction, two groups (Groups Re-Ext 4min MID and Re-Ext 20min MID) were injected (ip) with midazolam, and the remaining groups (Groups Re-Ext 4 min VEH and Re-Ext 20min VEH) received vehicle. Two hours later, all rats received control injections of whichever drug they did not initially receive, in order to control for any effects of the drug per se on test performance. On Day 5, all rats were tested in the context for $10 \mathrm{~min}$ in the absence of shock.

\section{Experiment 2}

On Days 1 and 3, all rats were placed in the context for $1 \mathrm{~min}$, before receiving a $0.5-\mathrm{mA}, 1$-sec footshock. Rats remained in the chambers for a further $2 \mathrm{~min}$, before being removed and returned to their home cages. On Day 4, rats received extinction training, which consisted of either a 4-min (Groups Ext 4min MID and Ext 4min VEH) or 20-min (Groups Ext 20min MID and Ext 20min VEH) nonreinforced exposure to the context. Ten minutes prior to the onset of re-extinction, two groups (Groups Ext 4min MID and Ext 20min MID) were injected with midazolam, and the remaining groups (Groups Ext 4min VEH and Ext 20min VEH) received vehicle. Two hours later, all rats received control injections of whichever drug they did not initially receive. On Day 5, all rats were tested in the context for $10 \mathrm{~min}$ in the absence of shock.

\section{Experiment 3}

On Day 1, all rats were placed in the context for $1 \mathrm{~min}$, before receiving a $0.5-\mathrm{mA}, 1-\mathrm{sec}$ footshock. Rats remained in the chambers for a further $2 \mathrm{~min}$, before being removed and returned to their home cages. On Day 2, rats in three groups received extinction training. This consisted of 5-min (Group Ext 5min), 10-min (Group Ext 10min), or 20-min (Group Ext 20min) nonreinforced exposure to the context. Rats in Group Ext Omin did not receive extinction, but did receive equivalent handling. On Day 3, all rats received identical conditioning as on Day 1, and on Day 4, they received extinction/re-extinction training. Extinction/ re-extinction training consisted of a 20-min nonreinforced exposure to the context. Ten minutes prior to the onset of extinction/ re-extinction, all rats were injected with midazolam. On Day 5 , all rats were tested in the context for $10 \mathrm{~min}$ in the absence of shock.

\section{Experiment 4}

On Day 1, all rats were placed in the context for $1 \mathrm{~min}$, before receiving a $0.5-\mathrm{mA}, 1$-sec footshock. Rats remained in the chambers for a further $2 \mathrm{~min}$, before being removed and returned to their home cages. On Day 2 all rats received extinction training. This consisted of a 5-min nonreinforced exposure to the context. On Day 3, all rats received identical conditioning as on Day 1, and on Day 4, three groups received re-extinction training. Re-extinction training consisted of 5-min (Group Re-Ext 5min), 10-min (Group Re-Ext 10min), or 20-min (Group Re-Ext 20min) nonreinforced exposure to the context. Ten minutes prior to the onset of re-extinction, all rats were injected with midazolam. Rats in Group Re-Ext 0min did not receive re-extinction, but were injected with midazolam and subjected to equivalent handling. On Day 5, all rats were tested in the context for $10 \mathrm{~min}$ in the absence of shock.

\section{Experiment 5}

On the morning of Day 1, all rats were exposed to the context for $8 \mathrm{~min}$ in the absence of shock. This pre-exposure has been shown to facilitate the acquisition of contextual fear (Kiernan and
Westbrook 1993) and was done in order to minimize potential freezing deficits as a result of surgery. Five hours later, rats were placed in the context for $1 \mathrm{~min}$, before receiving a $0.8-\mathrm{mA}, 1-\mathrm{sec}$ footshock. Rats remained in the chambers for a further $2 \mathrm{~min}$, before being removed and returned to their home cages. On Day 2 all rats received extinction training. This consisted of a 20-min nonreinforced exposure to the context. On Day 3, all rats received identical conditioning as on Day 1 , and on Day 4 , all rats received re-extinction training. Re-extinction training consisted of either a 4-min (Groups Re-Ext 4min MID and Re-Ext 4min VEH) or 20-min (Groups Re-Ext 20min MID and Re-Ext 20min VEH) nonreinforced exposure to the context. Ten minutes prior to the onset of re-extinction, two groups (Groups Re-Ext 4min MID and Re-Ext 20min MID) were given intra-BLA infusions of midazolam, and the remaining groups (Groups Re-Ext 4min VEH and Re-Ext $20 \mathrm{~min} \mathrm{VEH}$ ) were infused with vehicle. Six hours later, all rats received control infusions of whichever drug they did not initially receive, in order to control for any effects of the drug per se on test performance. On Day 5, all rats were tested in the context for $10 \mathrm{~min}$ in the absence of shock.

\section{Scoring and statistical analyses}

Freezing was used to assess conditioned fear. It was defined as the absence of all movement except those related to breathing (Fanselow 1980). Each rat was observed every 2 sec and scored as either "freezing" or "not freezing" by two observers, one of which was blind to group allocation. There was a high degree of agreement between the two observers, with a Pearson product moment correlation $>0.9$. The test data in each experiment were analyzed by a contrast testing procedure, which used the Bonferroni inequality to control the experiment-wise error rate. Contrast analysis allows us to test the statistical significance of particular between-group comparisons and their interactions with within-group trends at a user-defined error rate. Significance was set at $\alpha=0.05$.

\section{Acknowledgments}

This research was supported by a grant from the Australian National Health and Medical Research Council and by a scholarship to G.H. from Brain Sciences Institute UNSW.

\section{References}

Birk L. 2004. Pharmacotherapy for performance anxiety disorders: Occasionally useful but typically contraindicated. J Clin Psychol 60: 867-879.

Bouton ME. 1993. Context, time and memory retrieval in the interference paradigms of Pavlovian learning. Psychol Bull 114: 80-99.

Bouton ME, Bolles RC. 1979. Role of conditioned contextual stimuli in reinstatement of extinguished fear. J Exp Psychol Anim Behav Process 5: $368-378$.

Bouton ME, King DA. 1983. Contextual control of the extinction of conditioned fear: Tests for the associative value of the context. J Exp Psychol 9: 248-265.

Bouton ME, Ricker ST. 1994. Renewal of extinguished responding in a second context. Anim Learn Behav 22: 317-324.

Bouton ME, Kenney FA, Rosengard C. 1990. State-dependent fear extinction with two benzodiazepine tranquilizers. Behav Neurosci 140: $44-55$.

Bouton ME, Westbrook RF, Corcoran KA, Maren S. 2006. Contextual and temporal modulation of extinction: Behavioral and biological mechanisms. Biol Psychiatry 60: 352-360.

Bustos SG, Maldonado H, Molina VA. 2006. Midazolam disrupts fear memory reconsolidation. Neuroscience 139: 831-842.

Bustos SG, Maldonado H, Molina VA. 2009. Disruptive effect of midazolam on fear memory reconsolidation: Decisive influence of reactivation time span and memory age. Neuropsychopharm 34: 446-457.

Fanselow MS. 1980. Conditional and unconditional components of post-shock freezing. Pavlov J Biol Sci 15: 177-182.

Fritschy JM, Mohler H. 1995. GABA -receptor heterogeneity in the adult rat brain: Differential regional and cellular distribution of seven major subunits. J Comp Neurol 359: 154-194. 
Harris JA, Westbrook RF. 1995. Midazolam impairs the acquisition of conditioned analgesia if rats are tested with an acute but not a chronic noxious stimulus. Brain Res Bull 39: 227-233.

Harris JA, Westbrook RF. 1998. Benzodiazepine-induced amnesia in rats: Reinstatement of conditioned performance by noxious stimulation on test. Behav Neurosci 112: 183-192.

Harris JA, Westbrook RF. 1999. The benzodiazepine midazolam does not impair Pavlovian fear conditioning but regulates when and where fear is expressed. J Exp Psychol 25: 236-246.

Harris JA, Westbrook RF. 2001. Contextual control over the expression of fear in rats conditioned under a benzodiazepine. Psychopharmacology 156: $92-97$.

Harris JA, Jones ML, Bailey GK, Westbrook RF. 2000. Contextual control over conditioned responding in an extinction paradigm. J Exp Psychol Anim Behav Process 26: 174-185.

Hart G, Harris JA, Westbrook RF. 2009. Systemic or intra-amygdala injection of a benzodiazepine (midazolam) impairs extinction but spares re-extinction of conditioned fear responses. Learn Mem 16: $53-61$.

Helmstetter FJ. 1993. Stress-induced hypoalgesia and defensive freezing are attenuated by application of diazepam to the amygdala. Pharmacol Biochem Behav 44: 433-438.

Kiernan MJ, Westbrook RF. 1993. Effects of exposure to a to-be-shocked environment upon the rat's freezing response: Evidence for facilitation, latent inhibition and perceptual learning. Q J Exp Psychol [B] 46: 271-288.

Kim JH, Richardson R. 2008. The effect of temporary amygdala inactivation on extinction and reextinction of fear in the developing rat: Unlearning as a potential mechanism for extinction early in development. J Neurosci 28: 1282-1290.

Laurent V, Westbrook RF. 2008. Distinct contributions of the basolateral amygdala and the medial prefrontal cortex to learning and relearning extinction of context conditioned fear. Learn Mem 16: 96-105.

Laurent V, Westbrook RF. 2009. Inactivation of the infralimbic but not the prelimbic cortex impairs consolidation, and retrieval of fear extinction. Learn Mem 15: 520-529.

Laurent V, Westbrook RF. 2010. Role of the basolateral amygdala in the reinstatement and extinction of fear responses to a previously extinguished conditioned stimulus. Learn Mem 2: 86-96.

Laurent V, Marchand AR, Westbrook RF. 2008. The basolateral amygdala is necessary for learning but not relearning extinction of context conditioned fear. Learn Mem 15: 304-314.

Leung HT, Westbrook RF. 2008. Spontaneous recovery of extinguished fear responses deepens their extinction: A role for error-correction mechanisms. J Exp Psychol Anim Behav Process 34: 461-474.
Likhtik E, Pelletier JG, Paz R, Pare D. 2005. Prefrontal control of the amygdala. J Neurosci 25: 7429-7437.

Low K, Crestani F, Keist R, Benke D, Brunig I, Benson JA, Fritschy J, Rulicke T, Bluethmann H, Mohler H, et al. 2000. Molecular and neurolan substrate for the selective attenuation of anxiety. Science 290: $131-135$.

McDonald AJ. 1998. Cortical pathways to the mammalian amygdala. Prog Neurobiol 55: 257-332.

Morris RW, Furlong TM, Westbrook RF. 2005. Recent exposure to a dangerous context impairs extinction and reinstates lost fear reactions. J Exp Psychol Anim Behav Process 31: 40-55.

Pare D, Smith Y. 1993. The intercalated cell masses project to the central and medial nuclei of the amygdale in cats. Neuroscience 57: 1077-1090.

Paxinos G, Watson C. 1998. The rat brain in stereotaxic coordinates, 4 th ed. Academic, San Diego, CA.

Quirk GJ. 2002. Memory for extinction of conditioned fear is longlasting and persists following spontaneous recovery. Learn Mem $\mathbf{9}$ 402-407.

Quirk GJ, Mueller D. 2008. Neural mechanisms of extinction learning and retrieval. Neuropsychopharmacology 33: 56-72.

Rescorla RA. 2001. Retraining of extinguished Pavlovian stimuli. J Exp Psychol Anim Behav Process 27: 155-124.

Rescorla RA, Holland PC. 1982. Behavioral studies of associative learning in animals. Ann Rev Psychol 33: 265-308.

Rescorla RA, Wagner AR. 1972. A theory of Pavlovian conditioning: Variation in the effectiveness of reinforcement and nonreinforcement. In Classical conditioning II: Current theory and research (ed. AH Black, WF Prokasy), pp. 181-215. Appleton-Century-Crofts, New York.

Royer S, Martina M, Pare D. 1999. An inhibitory interface gates impulse traffic between the input and output stations of the amygdala. $J$ Neurosci 19: 10575-10583.

Rumelhart DE, Hinton GE, Williams RJ. 1986. Learning representations by back-propagating errors. Nature 323: 533-536.

Sanders SK, Shekhar A. 1991. Blockade of $\mathrm{GABA}_{\mathrm{A}}$ receptors in the region of the anterior basolateral amygdala of rats elicits increases in heart rate and blood pressure. Brain Res 576: 101-110.

Scheffé H. 1959. The analysis of variance. Wiley, New York.

Van Laar MW, Volkerts ER. 1998. Driving and benzodiazepine use: Evidence that they do not mix. CNS Drugs 10: 383-396.

Westbrook RF, Iordanova M, McNally GP, Richardson R, Harris JA. 2002. Reinstatement of fear to an extinguished conditioned stimulus: Two roles for context. J Exp Psycho Anim Behav Process 28: 97-110.

Received November 2, 2009; accepted in revised form January 27, 2010. 


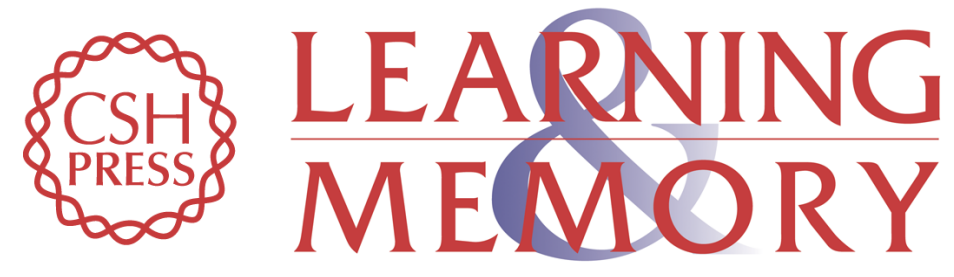

\section{Systemic or intra-amygdala infusion of the benzodiazepine, midazolam, impairs learning, but facilitates re-learning to inhibit fear responses in extinction}

Genevra Hart, Justin A. Harris and R. Frederick Westbrook

Learn. Mem. 2010, 17:

Access the most recent version at doi:10.1101/lm.1682410

References This article cites 39 articles, 7 of which can be accessed free at: http://learnmem.cshlp.org/content/17/4/210.full.html\#ref-list-1

License

Email Alerting

Receive free email alerts when new articles cite this article - sign up in the box at the Service top right corner of the article or click here. 